\title{
METALLURGY AND CLIMATE CHANGES - HEAT TRANSFER BY CONDUCTION
}

\section{Dan CONSTANTINESCU}

University Politehnica of Bucharest, Bucharest, Romania, EU, dconstantinescu@ecomet.pub.ro

https://doi.org/10.37904/metal.2019.687

\begin{abstract}
The present paper does not have in view the impact of metallurgical industry on the environment. We have in view some thermal models, used in the case of solid bodies like for example the steel, in order to analyze similar phenomena in the nature and the effect on the climate changes. But, in the case of a natural system, it is more complicate, having in view the properties of the rocks and of the air.

In the case of the conductivity of the steels, it is used the Laplace equation for the bidirectional conductivity and the theory of Debay and Einstein regarding the stream of the electrons. But, is it applicable in case of the rocks and of the soils? This is not very sure. In the article are used some experimental data regarding the temperature in soils and the temperature of the air. The data are obtained at research centre Abisko located near the Arctic Circle, Sweden. Tables and graphics are obtained and the results are analyzed. Some conclusions regarding the heat transfer from the interior levels of the rocks are presented. However, the conclusions are not the final conclusions and more data and mathematical models are necessary. Therefore, we propose to follow the researches in two directions. It means, the theory of heat transfer in solid bodies, and the second direction regard the data of heat transfer from the soil surface to the air. It can be employed a quantitative approach, including numerical solution and theoretical aspects of heat transfer.
\end{abstract}

Keywords: Metallurgy, steel, conductivity, climate changes, mathematical model

\section{THERMAL CONDUCTIVITY IN SOLID MATERIAL}

The concentration of heat flux by conductivity, $q$, is in agreement with the Fourier hypothesis. It is proportional to the temperature gradient " $\operatorname{grad}(T)$ " and it is connected with the thermal conductivity coefficient, $\lambda$ (coefficient of proportionality):

$q=-\lambda \operatorname{grad}(T)$

Taking in view a three-dimensional temperature field without internal sources of heat, it is possible to express the dependence among temperature $T$, coordinates $x, y, z$, and the time $\tau$ by the differential equation:

$$
\frac{\partial T}{\partial \tau}=\frac{\lambda}{c \cdot \rho} \nabla^{2} T
$$

The symbol $\nabla^{2}$ is the Lapalace operator: $\nabla^{2} T=\frac{\partial^{2} T}{\partial x^{2}}+\frac{\partial^{2} T}{\partial y^{2}}+\frac{\partial^{2} T}{\partial z^{2}}$.

But, in the case of the heat transfer in soils and rocks, the internal sources are frequently present.

In this case, [1] for the stationary conductive flow, it can be written the equation (3):

$$
\frac{\partial^{2} T}{\partial x^{2}}+\frac{\partial^{2} T}{\partial y^{2}}+\frac{\partial^{2} T}{\partial z^{2}}+\frac{q_{v}(x, y, z)}{\lambda}=0
$$

The humidity, the thermal capacity and the density of the rocks also influences the heat transfer. 
The calculations and the model of Debay can be applicable for some cases [2]. The Debye model is a solidstate equivalent, where one treats electromagnetic radiation as a photon gas. The Debye model treats atomic vibrations as phonons in a box (the box being the solid). Most of the calculation steps are identical as both are examples of a mass less gas with linear dispersion relation. Unlike electromagnetic radiation in a box, there is a finite number of phonon energy states because a phonon cannot have arbitrarily high frequencies. Its frequency is bounded by the medium of its propagation-the atomic lattice of the solid.

So, if we analyse the thermal conductivity of the steels it is possible to call the "thermal conductivity" as "electron conductivity". The kinetic theory analyzes the motion of electrons in solids in electric and magnetic fields made form atoms of a mass but also in presence of the outer temperature field, e.g. in presence of a gradient of temperatures.

Following the Boltzmann kinetic equation it is possible to describes the motion of the electrons in the steels under these conditions [3]:

$$
\left(\frac{\partial f_{0}}{\partial E}\right) v_{k}\left[-\frac{\varepsilon(k)-\mu}{T} \nabla T+e\left(E-\frac{1}{c} \nabla \mu\right)\right]=-\frac{\partial f_{k}}{\partial \tau}+v_{k} \frac{\partial g_{k}}{\partial r} \frac{e}{\hbar c}\left[v_{k} E\right] \frac{\partial g_{k}}{\partial k}
$$

where

$f_{0}$ is the function of distribution of the probability of the level with the energy $E$

$v_{k}$ - vector of velocity, in core the gradient of energy in $k$ - space

$\varepsilon(k)$ - elongation of the $k$ - space

$\mu$ - Fermi level, in core the chemical potential or the free energy calculated for one electron;

$f_{k}$ - non-equilibrium function of the distribution of the probability of maximum concentration of the electron in state $k$ in surrounding of the point $r$,

e- the vector of the electric field;

$c$ - the velocity of light;

h - Planck constant; $\left(6.626070150(81) \times 10^{-3}\right)$ J.s (for 2018)

$\hbar=\mathrm{h} / 2 \pi$ (Dirak constant)

$g_{k}=f_{k}-f_{0}$

Analyzing the equation (4), the problem is: how can it be applied in the case of the heat transfer in geological layers.

\section{ESTABLISHING OF THE HEAT TRANSFER IN THE CASE OF A SOIL - AIR SYSTEM}

In order to analyze the heat transfer in the soil-air system, it is necessary to have in view:

a) supposing an inhomogeneous plan system, composed by " $n$ " layers with thickness $\delta_{1}, \delta_{2}, \delta_{3}, \ldots \delta_{n}$ and thermal conductivities $\lambda_{1}, \lambda_{2}, \lambda_{3}, \ldots \lambda_{n}$. An inhomogeneous solid plan is a system with composite structures, represented in several layers, with or without perfect contact between them [4]. Each layer is considered to be homogeneous. Heat propagation will be considered unidirectional or will be approximated with a one-way process (Figure 1). Figure 2 presents an area from Abisko Reservation which was visited in view of the anayse the heat transfer by conduction. Thermal contact between layers is imperfect. The conduction equation is the equation (5). 


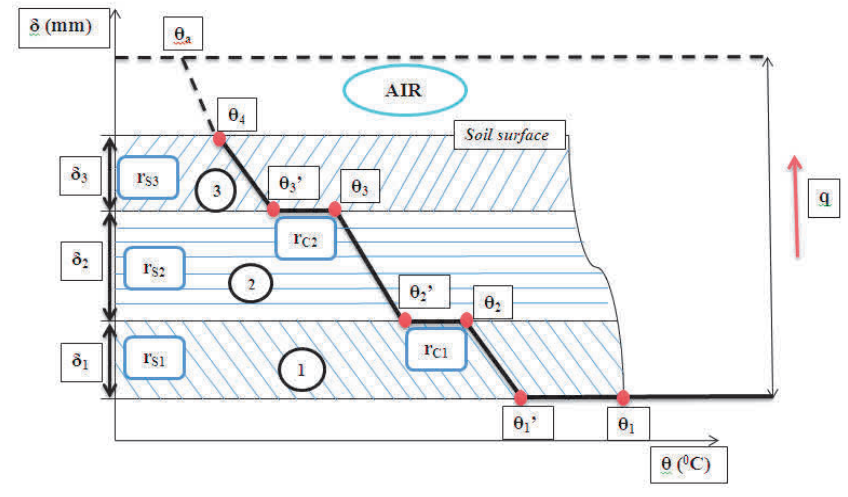

Figure 1 Temperature variation in geological layers with different physical and thermal properties (3 layers)

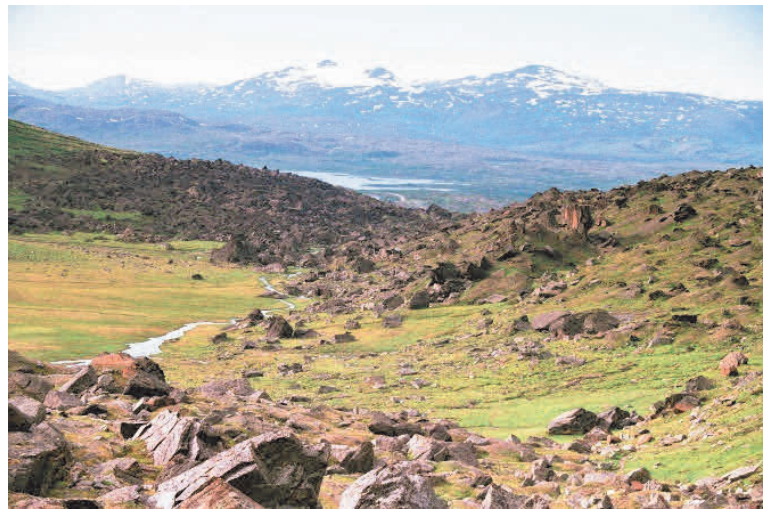

Figure 2 Kärkevagge geologic reservation, included in Abisko Reservation

$q=\frac{\theta_{1}-\theta_{n}}{\frac{\delta_{1}}{\lambda_{1}}+r_{c 1}+\frac{\delta_{2}}{\lambda_{2}}+r_{c 2}+\ldots+\frac{\delta_{n-1}}{\lambda_{n-1}}}$

where $r_{c 1}, r_{c 2}, \ldots$ are thermal contact resistance.

b) If the surface temperature of the soil is higher than the air temperature (Figure 3), then it is possible to calculate the temperatures and the thermal flow from the interiors of the geological layers to the air. The thermal flow is given by $[5,6]$ :

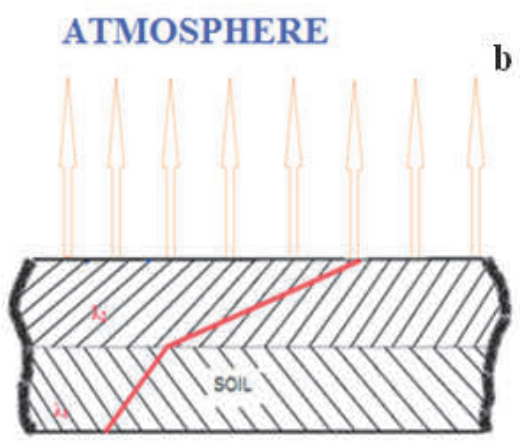

Figure 3 The sense of the thermal flow - the conductive thermal flow from the inside of the soil to the soil surface (it is important especialy during the cold periods)

$q_{n-(n-i)}=\kappa\left(\theta_{n}-\theta_{n-i}\right)$

where $\kappa$ is global coefficient of heat transfer in solid soil

For example, in the case of a geological area composed by 3 different layers, applying the limit conditions, it is obtained the equation (7):

$\kappa=\frac{\lambda_{2}}{\delta \cdot \tau_{c}} \int_{0}^{\tau_{C}} e^{C \cdot \tau}[1-\Phi(\sqrt{C \cdot \tau})] d \tau$

where

TC - time, measured during the experiment or time unit 
$C=a_{3} \cdot \chi^{2}$

$a_{3}$ - thermal diffusivity for layer 3

$\chi$ - relative coefficient of heat transfer (thermal conductance), depending on the thermal resistance, 1

$$
\mathrm{r} ; \quad \frac{r_{t}}{\lambda_{3}}=\frac{2 \lambda_{2}}{\delta \cdot \lambda_{3}}
$$

$\Phi$ - Gauss coefficient [7]

It is noted: the "coefficient of heat penetration", b3 in the case of three layer system:

$b_{3}=\frac{\lambda_{3}}{\sqrt{a_{3}}}=\sqrt{\lambda_{3} \cdot c_{3} \cdot \delta_{3}}$

And

$\Phi(n)=\frac{2}{\sqrt{\pi}} n\left(1-\frac{n^{2}}{3 \cdot 1 !}+\frac{n^{4}}{5 \cdot 2 !}-\frac{n^{6}}{7 \cdot 3 !}+\cdots\right)$

The final form of the coefficient $\mathrm{k}$ is:

$\kappa=\frac{b_{3}}{2 \sqrt{\tau_{C}}}\left\{\frac{e^{n^{2}}}{n}[1-\Phi(n)]-\frac{1}{n}+\frac{2}{\sqrt{\pi}}\right\}$

At the separation limit between the soil surface and the atmosphere, a part of thermal flow is absorbed by the gases. The absorption process by radiation depends on the partial pressure of $\mathrm{CO}_{2}$ and $\mathrm{H}_{2} \mathrm{O}$ [5]. The absorbed thermal energy by radiation, $Q_{a b s}$, is equal to the quantity of the energy that the soil could receive from gases (Figure 1, equation 11):

$Q_{a b s}=\alpha_{a-S} \cdot \varepsilon_{S} \cdot S \cdot\left(\theta_{a}-\theta_{S}\right)$

where

$\alpha_{\text {a-s: }}$ : coefficient of the heat exchange from the air (atmosphere) to the soil surface, or from the soil to the atmosphere, depending on the thermal heat sense; $\left(\mathrm{kJ} \cdot \mathrm{m}^{-2} \cdot \mathrm{h}^{-1} \cdot \mathrm{K}-1\right)$

$\theta_{a}$ : temperature of the air

$\theta$ s: temperature of the soil surface

S: soil surface area, $\left(\mathrm{m}^{2}\right)$

Es: coefficient of the thermal emissivity of the soil surface; we have to estimate here the local albedo value

\section{EXPERIMENTAL RESEARCHES REGARDING THE VALUES OT THE TEMPERATURE}

Analyzing the particularities of the Torneträsk Lake (173m deep) and the environment between Abisko and Bjötkliden, Mortimer [7], establish the values of the temperatures between 0 and $1.5^{\circ} \mathrm{C}$, increasing with the deepness (Figure 4).

Following the researches of Salberg [8], regarding the particularities of the area of Abisko Reservation, the heat transfer, including the water of the lakes, is strongly influenced by the seasons and the particularities of the air. It is interesting to analyze the heat flux, established with a mathematical model. In the Figure $\mathbf{5}$ are presented the values of the heat flux for the lake Akkajaure for the period 1999 - 2002 [7]. 

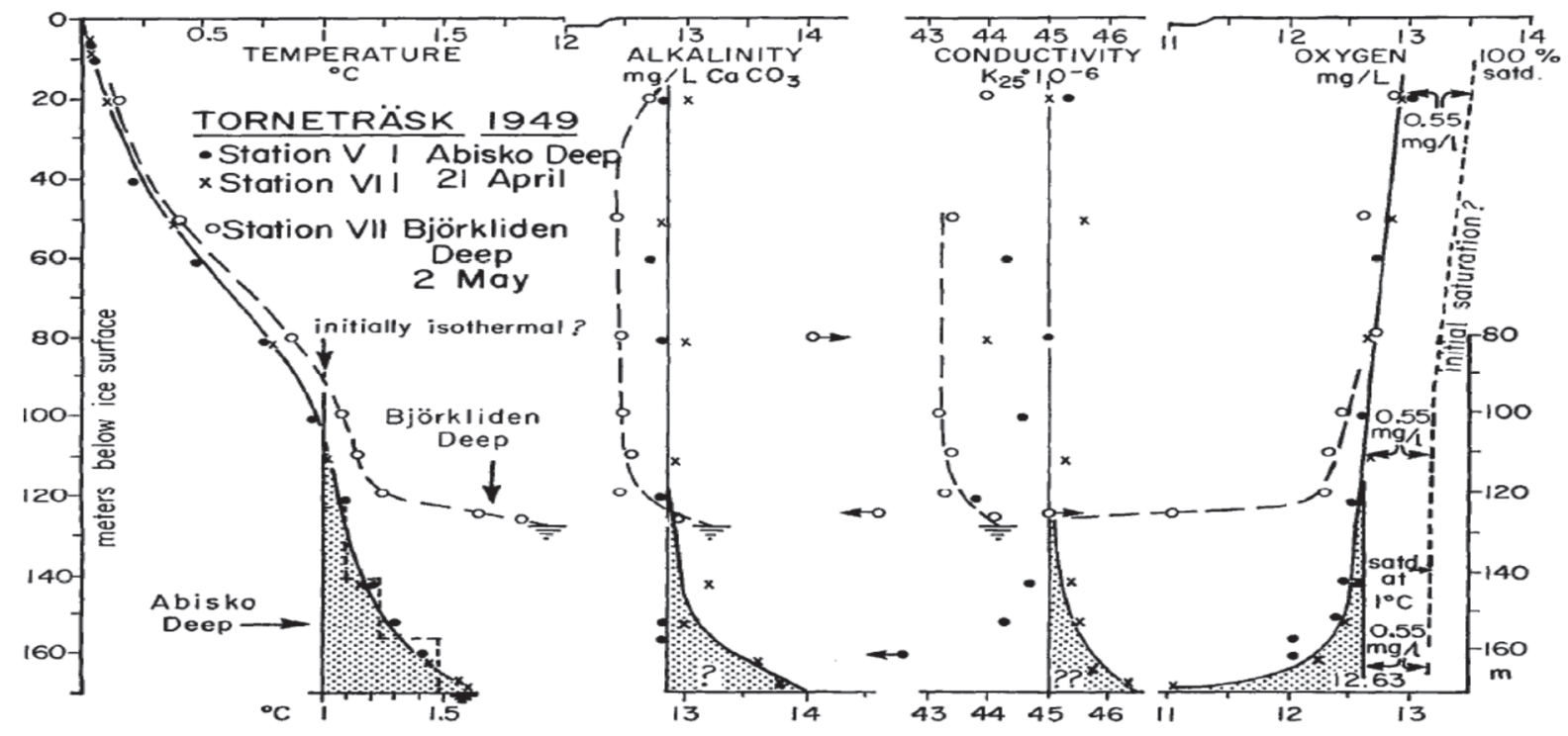

Figure 4 Depth distribution of temperature in the Lake Torneträsk, Lapland, Sweden (redrawn from Mortimer and Mackereth)
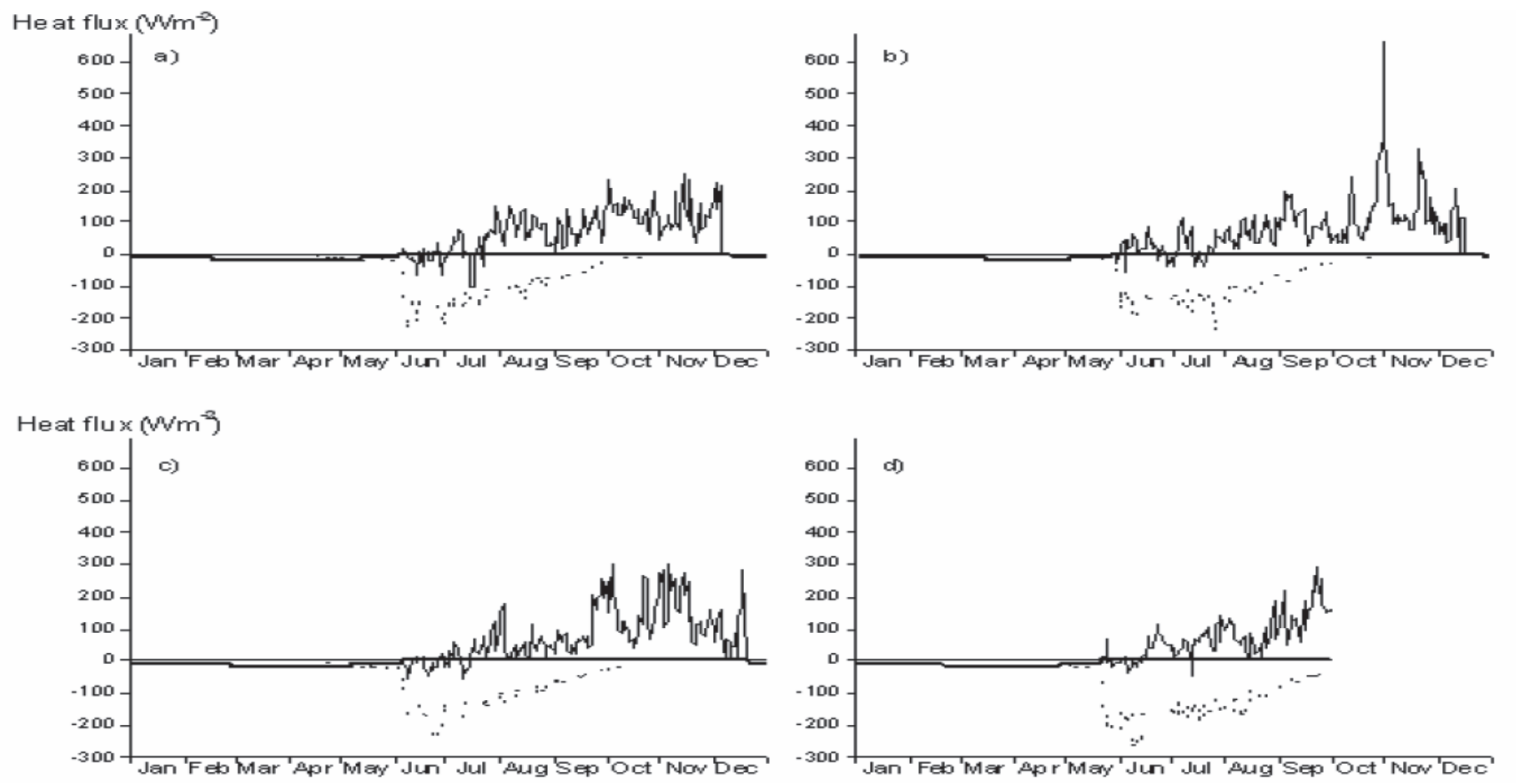

Figure 5 The calculated heat fluxes for the years 1999, 2000, 2001, 2002 (after Salberg [8]). Daily mean values of the sum of the sensible heat flux, latent flux and the long wave radiation.

It is interesting to compare the situation presented in Figures $\mathbf{4}$ and $\mathbf{5}$, with the registered values for the soil temperature, but also with the values of the Torneträsk Lake measured by the authors of the present paper for the period during 2017.

\section{EXPERIMENTAL RESEARCHES OF FOR THE ACTUAL PERIOD}

During the visits and the expeditions in Abisko Reservation in the period 2006-2017, the authors of the present paper have obtained many data regarding for the air, soils, waters and climate changes $[4,9]$.

The soil temperatures were recorded in Abisko Research Station since 1982, when the investigated deepness fluctuated between $0.2 \mathrm{~m}$ and $1 \mathrm{~m}$ and only later, the soil temperatures were measured for the deepness of 
$0.05 \mathrm{~m}$. The obtained data have numerous applications, as the explanation of the past distribution of the forest and permafrost and are currently used as a predicting model to the future ecosystem responses to the climate changes $[9,10]$. The overall spectrum suggests the existence of degree of deterministic forms of climatic change, but sufficient nonsystematic variability to place significant constraints both on the extent to which climate can be predicted, and on the extent to which significant events in the paleoclimatic record can ever manage to be assigned specific causes [10].

For example, in Figure 6 are presented the values of the temperature of the soils for the year 1982 and in Figure 7 the evaluation of the soil temperature for the period 1982-2012.

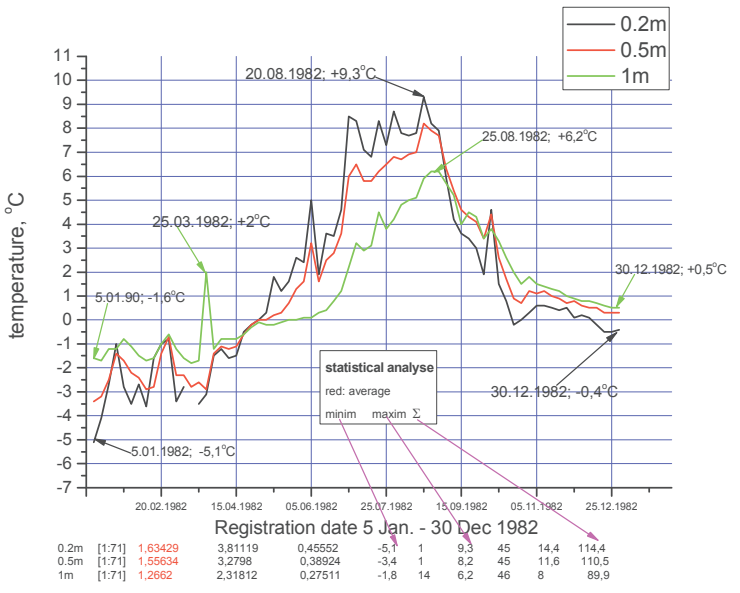

Figure 6 The temperatures of the rock registered at Abisko Station during the year 1982

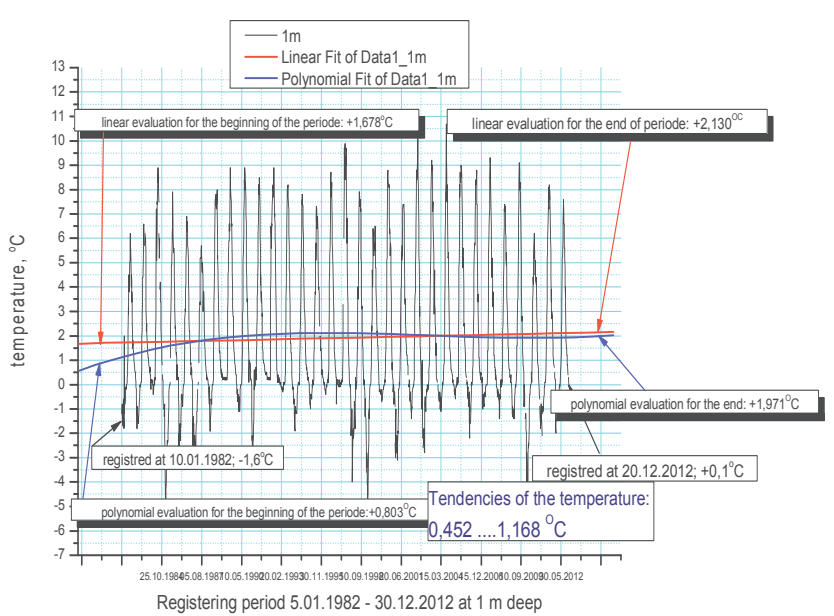

Figure 7 Evaluation of the tendencies of the soil temperatures at $1 \mathrm{~m}$ deepness for the period 1982-2012

For the last period of time, the trend of the evolution of the temperature is very similar as for the period of 19822012. In Figure 8 is presented the evaluation for the temperature having in view also the values of the air temperature.

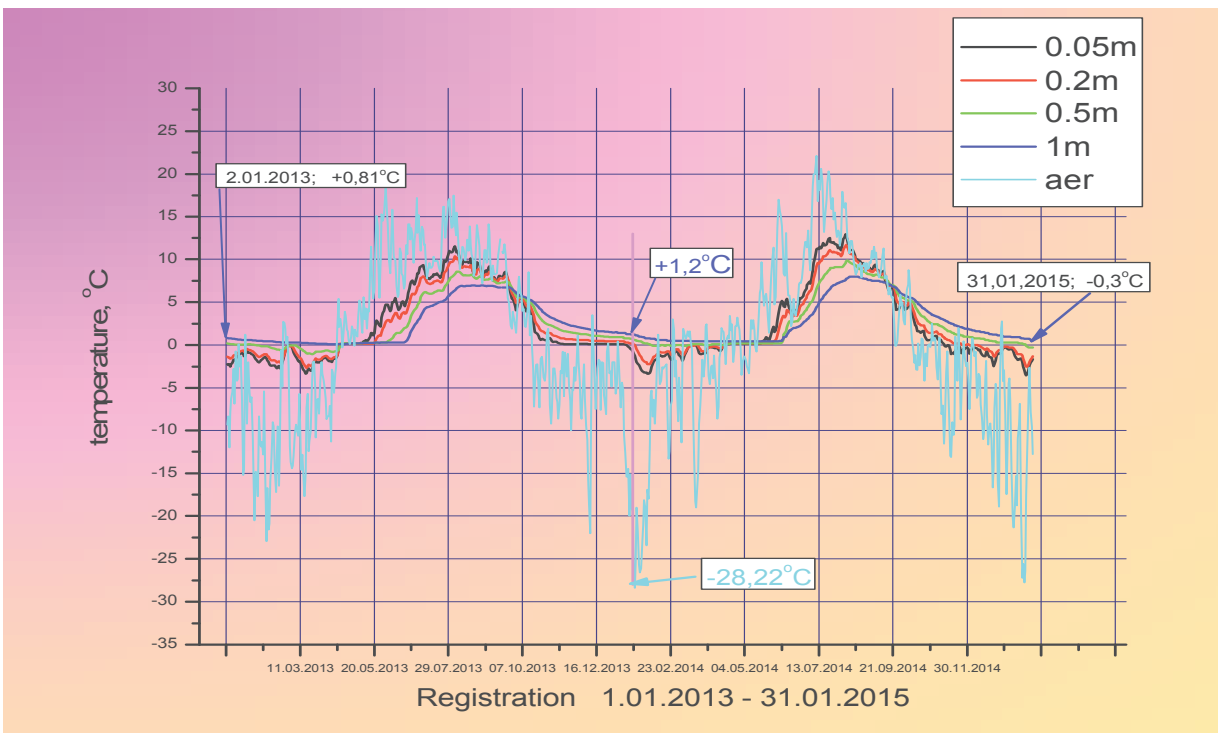

Figure 8 Evaluation of the temperatures of the geological layers depending on the deepness and the values of the air temperature [9] 


\section{CONCLUSIONS}

It can be remarked that, in order to obtain more exact results for the calculation of the thermal conductivity, it is necessary to establish different equation, depending not only on the quality of solid body, but also on the level of the temperature. In the case of the experiments, the used installations will work applying different relations for the thermal conductivity, following the Debay theory. In the case of the heat transfer in soils and rocks, the internal sources ar frequantely present. In this case, for the stationary conductive flow, it can be writen the equation (3). The temperature fluctuations of the geological layers are reducing with the increase of the deepness. As physiacal parameters, the humidity, the thermal conductivity and the density highly influences the thermal flow. A similar activity of the thermal flow can be remarked in the case of solid geological layers and in the water of the lakes (Torneträsk and Akkajaure). From this, we can conclude the significance of the heat transfer to the atmosphere. So, we consider that, it can be established a similarity from mathematical point of view between the models for the conductive flow in steels and in the geological layers. It is important to analyse the thermal processes in the sub polar zones, because this areas strongly influences the climate changes in the southern area of Europe.

\section{REFERENCES}

[1] POPA, B., MADARASAN, T., POPA, M. Manualul Inginerului Termotehnician, Editura Tehnica, Bucuresti, 1986, vol. 1, pp. 289-318.

[2] Wikipedia, the free Encyclopaedia. Debay model: https://en.wikipedia.org/wiki/Debye model

[3] Quantum transport, Fall 2008/8513: http://www.mit.edu/ levitov/8513/lec56.pdf

[4] ECKERT, R. G., DRAKE, R. M., (1972), Analysis of heat transfer, McGraw Hill, New York.

[5] CONSTANTINESCU, D., CARLAN, B.A. Preliminary study concerning the role of the thermo-physical factors during the heating process of the heavy ingots for forging. Metalurgia International. 2013. vol. 2, pp. 158-164.

[6] CONSTANTINESCU, D. Cercetări privind îmbunătățirea parametrilor de funcţionare ai agregatelor tehnologice de încălzire a materialelor metalice supuse deformării prin laminare, Thesis, Bucureşti, "Universitatea Politehnica Bucureşti", 1997.

[7] MORTIMER, C.M. Chemical exchanges between sediments and water in the Great Lakes - speculation on probably regulatory mechanisms. Milwaukee: Center of the Great Lakes Studies, University of WisconsinMilwaukee, 1971.

[8] SALBERG, J. Physical modeling of the Akkajaure reservoir. Hydrol. Earth Sci., 2003. vol. 7, no. 3, pp. $268-282$.

[9] CONSTANTINESCU, D., CARLAN, B.A., KRISTOFFERSSON, A. Preliminary remarks about the heat transfer and soil properties in Abisko National Park. Cluj: "Environment and Progress", University Babeş-Boliay, 2015.

[10] MITCHELL J.M. An overview of climatic variability and its causal mechanisms. Cambridge: Cambridge University Press, 1976. pp. 481-494. 